\title{
Eliciting Patients' Health Concerns in Consulting Rooms and Wards in Vietnamese Public Hospitals
}

\author{
Huong Thi Linh Nguyen ${ }^{1 *}$, Gavin Austin¹, Dung Duc Chau ${ }^{2}$, Hien Quang Nguyen ${ }^{3}$, Khanh Hoang Bao Nguyen ${ }^{4}$, Manh The Duong ${ }^{5}$ \\ ${ }^{1}$ University of Southern Queensland, Toowoomba, Australia \\ ${ }^{2}$ Thua Thien Hue Vocational College, Thua Thien Hue Province, Vietnam \\ ${ }^{3}$ Thua Thien Hue Hospital of Rehabilitation, Thua Thien Hue Province, Vietnam \\ ${ }^{4}$ Hue Industrial College, Hue City, Vietnam \\ ${ }^{5}$ Au Lac Company, Hue City, Vietnam
}

Corresponding Author: Huong Thi Linh Nguyen, E-mail: U1081741@umail.usq.edu.au

\section{ARTICLE INFO}

\section{Article history}

Received: December 08, 2017

Accepted: January 29, 2018

Published: March 01, 2018

Volume: 7 Issue: 2

Advance access: February 2018

Conflicts of interest: None

Funding: None

\begin{abstract}
This article examines the doctor's elicitation of the patient's presenting health concern in two clinical settings in the Vietnamese public hospital system: the consulting room and the ward. The data were taken from 66 audio-recorded consultations. Our analysis shows that the elicitors used by the doctor in the consulting room often communicate a weak epistemic stance towards the patient's health issue, while those used in the ward tend to signal a strong epistemic stance. In addition, this contrast between the elicitors employed in the consulting room and the ward is evident in our data regardless of whether the consultation is a first visit or a same follow-up (in which the doctor is the same one that treated the patient on their last visit), though the contrast is less clear for different follow-ups (in which the doctor has not treated the patient before). An additional finding is that the clinical setting has some bearing on the use of inappropriate elicitation formats (in which the doctor opens the visit with an elicitor which is more appropriate for another type of visit). The precise way in which each of the consulting room and the ward operates is, of course, a feature of the Vietnamese public hospital system itself. Hence, the overall contrast between the elicitors and elicitation formats used in these two settings illustrates how, on a more general level, the institutional context can have an impact on doctor-patient communication.
\end{abstract}

Key words: Vietnamese Public Hospital System, Doctor-Patient Communication, Problem Elicitation, Clinical Setting, Institutional Context, Conversation Analysis

\section{INTRODUCTION}

Seeking information about the patient's health problem is the doctor's main activity in a medical encounter (Silverman, Kurtz \& Draper, 2013), and is a critical step in generating successful treatment outcomes (Dyche \& Swiderski, 2005; Robinson \& Heritage, 2005). The significance of the doctor's elicitation of the patient's concerns is evidenced by the fact that it tends to occur relatively early in the consultation (Byrne \& Long, 1976): as soon as the doctor and the patient have greeted each other, the doctor launches directly into this stage of the consultation in order to establish the patient's reasons for their ${ }^{1}$ visit, and to set the scene for the rest of the consultation. The exact way in which the doctor designs their information-seeking utterances can also determine how the patient presents their concerns in response (Robinson, 2006).

While several studies have looked at problem elicitation in doctor-patient communication from one angle or another (Heritage \& Robinson, 2006; Park, 2009; Pham, 2014; Robinson, 2006; White, 2011), we know of no study that has been concerned specifically with examining how the doctor's elicitation of the patient's health concern might be shaped by the clinical setting in which this strategy is employed. The main goal of this study is to address this deficit within research on problem elicitation.

Moreover, this issue is examined in the Vietnamese context specifically. Within research dealing with medical communication in general, this cultural context has so far attracted relatively little interest among scholars. The studies in question have been done overseas (e.g., in the USA) and in Vietnam. ${ }^{2}$ In the overseas context, researchers have looked at how patients describe their experiences with depression (Fancher, Ton, Le Meyer, Ho, \& Paterniti, 2010) and cancer screening (Nguyen, Barg, Armstrong, Holmes, \& Hornik, 2007), and how they employ conversational constraints in medical interactions (Tran, 2009). Studies in Vietnam have explored doctor communication styles (Nguyen, 2012), and doctors' initiation of information-seeking moves (Pham, 2014). In the present study, we seek to increase the relatively paltry amount of research on Vietnamese 
doctor-patient discourse in general, and, as a result, make scholarly coverage of this form of discourse more representative cross-culturally.

Quite apart from this dearth of research interest, the Vietnamese context is a suitable one in which to investigate problem elicitation in different clinical settings. The consulting room is the first contact point for all patients once they go to a public hospital in Vietnam. After receiving a check-up, the patient is classified as an inpatient, outpatient, or consulting patient. A consulting patient leaves the hospital, while an inpatient or outpatient moves to a different ward to be re-examined by a doctor there. The fact that a ward patient has already been examined is significant, as it might be expected to create some interesting contrasts in the doctor's use of elicitors between the two settings of interest in this study.

One feature of work on doctor-patient discourse in the Vietnamese cultural context worth mentioning is that little research in this area has adopted Conversation Analysis (CA) as its analytical framework (for a comprehensive survey of how this framework has been used in research on medical communication more broadly, see Gill \& Roberts, 2013). The present study is intended to fill this gap.

\section{PREVIOUS RESEARCH ON THE DOCTOR'S INITIATION OF THE PATIENT'S PRESENTING CONCERN}

How the doctor designs their elicitation questions has been documented extensively in both Western and non-Western medical contexts. In the former context, Heritage and Robinson (2006) propose a typology of questions that doctors employ to elicit the patient's concerns. Five question types are identified: (i) open questions and ones in a 'tell me about X' format (e.g., 'Tell me about this pain you are getting'), both of which are used for general inquiries; (ii) closed questions to request (dis)confirmation related to the patient's medical problems (e.g., 'So you're sick today, huh?'); (iii) closed questions to request (dis)confirmation regarding concrete symptoms (e.g., 'You slipped and fell four weeks ago?'); (iv) 'How are you?' questions to elicit general assessments rather than presentations of concerns; and (v) closed questions to take the patient's medical history (e.g., 'You have any fever?').

In another project concerned with the doctor's design of elicitation questions, Robinson (2006) identifies three different formats: (i) open- or closed-ended questions for dealing with new concerns (i.e., ones presented for the first time to a specific doctor or clinic), (ii) open questions for eliciting follow-up concerns (i.e., ones already dealt with in previous visits, and now followed up for the sake of the ongoing management of the patient's treatment), and (iii) open or closed questions for indexing chronic-routine concerns (i.e., ones dealt with on a regular basis). The first format communicates the doctor's lack of knowledge of the patient's health concerns, while the second displays the doctor's pre-existing knowledge of these problems. The third format encompasses both of these scenarios, as illustrated in Extract 1. This patient $(\mathrm{P})$ has come for a blood pressure re-check (example from p. 38).

\section{Extract 1}

$3 \mathrm{D}^{3} \quad$ (Eh) So what's new.

$4 \quad(0.2)$

5 P: Nuh I just came in fer thuh blood pressure reche:ck, $6 \quad($.

$7 \mathrm{D}: \quad \mathrm{Mm} \quad[\mathrm{hm}:, \quad]$

$8 \mathrm{P}$ [Which I] guess was hi:gh,

The elicitor "So what's new" looks for a report of new concerns. The doctor (D) employs this questioning approach because this patient may not necessarily have come only for the blood-pressure check, but may be seeking treatment for a new concern as well.

While the studies above deal with primary-care settings, White (2011) focuses on the opening elicitors used in surgeon-patient consultations in New Zealand. As these visits take place in the surgery setting, the patients have to be referred by another general practitioner (GP) or specialist. This creates two distinctive formats for the opening elicitor: 'in your own words' elicitors and referral-based elicitors. In addition, like the primary-care doctors in Heritage and Robinson (2006) and Robinson (2006), the surgeons in White's study used open problem presentations, 'How are you?' questions, and follow-up elicitors. Extract 2 exemplifies a referral-based elicitor (example from p. 102).

\section{Extract 2}

$1 \mathrm{SG}$ : 'i'm doctor jess abbott i'm[(one of the breast surgeons?) $]^{\circ}$
$2 \mathrm{P}:$
$[<$ hi i'm stacyi $>$ ]

$3 \mathrm{SG}: \quad{ }^{\circ}$ 'll just flip that round so $\mathrm{i}$ can sit and talk

4 to you $i^{\circ}(0.9) \uparrow n: 0: w$ your $g$ p's written us a letter to say

5 you've noticed a problem with yuh breast.

$6 \mathrm{P}$ : $\quad$.oh 'yeah the 'uhm: (0.2) right breast's uh (.) nipple's

$7 \quad$ inverted

$8 \mathrm{SG}$ : $\mathrm{mhm}$

The surgeon (SG) alludes to a letter from the patient's GP in order to initiate the problem presentation (lines 3-5). White states that this kind of elicitor leads the patient to agree with the surgeon, plus encourages the patient to present their health concern without the need for further elicitation.

Other studies have been done in the non-Western context. Park (2009) observed different patterns of opening elicitor in his large project on the grammar and social organisation of actions in the Korean primary-care setting. Park found that the format '(name of patient) + topic marker' recurred in three visit types (i.e., first, follow-up, and routine visits). Other formats included (i) 'Where does it hurt?' and 'Why did you come in?' for first visits; (ii) 'How are you feeling?' and 'Other' (e.g. a summary of a past visit) for follow-ups; and (iii) 'You need X, right?', 'Other' (e.g. 'Did you eat breakfast today?/How are you feeling?'), and 'No solicitation' for routine visits. Pham (2014) investigated Vietnamese physicians' initial moves to elicit the patient's presentation of their concerns in first visits. Using a pragmatic approach to analysing the discourse in her 
study, she discovered that the four most frequent patterns of physician elicitor were (i) directly asking about the patient's pain/illness (e.g., 'How is the pain?/What is the illness?'); (ii) asking about the patient's health issue (e.g., 'What is the matter/problem?); (iii) asking what brought the patient in, or why the patient came in (e.g., 'Why did you come (for an examination)?'); and (iv) asking how they can help (e.g., 'How can I help (you)?'). Pham concludes that the physician's choice of information-seeking act is culturally and linguistically bound. That is, physicians often presuppose that patients meet them to address biomedical concerns only, so they tend to formulate their information-seeking moves accordingly. At the same time, the Vietnamese patients in her study did not tend to offer clarification directly even when their concerns were psychosocial. This may have had an adverse effect on the doctor's ability to elicit the full spectrum of information and provide optimal treatment.

This review has shown that doctors utilise a variety of elicitors in initiating the patient's problem presentation. More particularly, in each of Park (2009) and Robinson (2006), there is some association between the type of elicitor used by the doctor on one hand and the visit type on the other. However, to the best of our knowledge, no study has explored the possibility that this choice might also depend on the clinical setting. In the present study, we aim to remedy this research deficit by comparing the doctor's elicitation of the patient's presenting concerns in two primary-care settings within the Vietnamese public hospital system: the consulting room and the ward.

\section{DATA AND METHOD}

The data was taken from 66 consultations involving 15 general practitioners and 66 of their adult consulting patients, inpatients, and outpatients at the Consultation and General Practice Units of two public hospitals in Vietnam. The data were collected between June and August, 2016. Ethical clearance for the study was granted by the University of Southern Queensland. The transcription notation used in this study is derived from Jefferson (2004), except that one symbol (i.e., the hash (\#) sign) has been added to enclose the swallowed utterance or part thereof. Conversation Analysis is adopted as our framework for examining the consultations. In this study, we do not discuss all the visits in our data, but only use ones that contain clear examples of the phenomena being discussed. Because it is not compulsory for the patient to make an appointment in this hospital system, the patient is allocated to a doctor who happens to be available. Their follow-up visit thus could be with the same doctor as their previous visit, or with a different doctor. For this reason, the visits in our data fell into three categories (see Table 1): first visit, follow-up visit with the same doctor (SF), and follow-up visit with a different doctor (DF).

\section{ANALYSIS}

In this section, we analyse representative examples of problem elicitation in the consulting room and the ward. Within
Table 1. Inventory of visit types occurring in the consulting room and the ward

\begin{tabular}{lccc}
\hline Visit types & $\begin{array}{c}\text { First } \\
(\mathbf{N}=\mathbf{3 5})\end{array}$ & $\begin{array}{c}\text { DF } \\
(\mathbf{N}=\mathbf{2 2})\end{array}$ & $\begin{array}{c}\text { SF } \\
(\mathbf{N}=\mathbf{9})\end{array}$ \\
\hline Consulting room $(\mathrm{N}=28)$ & 13 & 11 & 4 \\
Ward $(\mathrm{N}=38)$ & 22 & 11 & 5 \\
\hline
\end{tabular}

each setting, the three kinds of visit (i.e., first visit, SF, and DF) are dealt with in turn.

\section{Consulting Room}

As the consulting room is the first point of contact for the patient when they enter the hospital, the doctors at the consulting room receive first-time patients and follow-up ones.

\section{First visits}

The elicitation of new concerns occurs in a first visit, when the doctor meets a new patient. This patient either has come to the current hospital for the first time, or has been to this hospital before. In the latter case, they present their new concerns for the first time either to the same doctor (i.e., one they have met before) or to a different doctor. In other words, they have not discussed their health concern with a medical professional in that hospital before. Consider Extract 3. This encounter is between doctor Hoang and patient Mi. Mi has been suffering from physical weakness lately, and her face is covered in pimples.

Extract 3

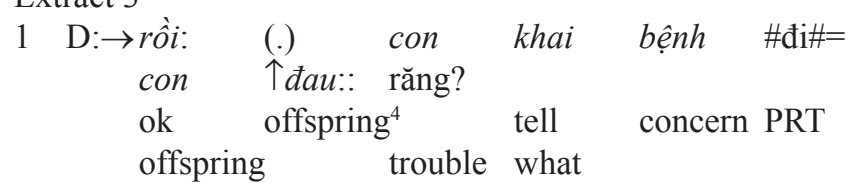

'OK. Tell me about your health concerns. What seems to be the trouble?'5

$2 \mathrm{P}: \quad u \cdots m$ (0.9) $d a$ (.) $c o n$ bũ $a+n i=6 c o n$

hay

mmm HON offspring lately of f -

spring usually

3 nguời hay suy+nhwợc $a_{i} \quad$ (0.2)

body usually weak PRT

'I've been feeling physically weak lately'

4 lại là con sợ $\quad{ }^{\circ} \mathrm{co}: \mathrm{O}^{\circ} \quad$ (1.0)

$u:: h \quad(0.2)$

and COP offspring worry

offspring uh

5 về $\quad$ (.) Tụ + nhiên cái

mạt con

about for+some+reason CLA face off spring

6 tụ+ + nhiên nổi- (.) mu- mun

(cưng) luôn,

for + some + reason break + out pimple lots

PRT

'and I'm worried because, for some reason, my face's broken out in lots of pimples' 
Right at the outset of the consultation, Hoang uses the appositional beginning (Sacks, Schegloff \& Jefferson, 1974) rồi: ('OK') as a turn-entry device to project two general-inquiry questions (Heritage \& Robinson, 2006) consecutively. This initiates the problem presentation (line 1). The first question, con khai bệnh đi= ('Tell me about your health concerns'), is latched (marked by ' $=$ ' in the transcription) to the second question, con đau răng? ('What seems to be the trouble?'). Both questions are general in the sense that Hoang has little knowledge of Mi's concern. This makes Mi's description of her problem a relevant response. These questions invite Mi to present her concern immediately, formulate Hoang's agnostic stance vis-à-vis the precise nature of Mi's medical condition, and license her presentation of her concern in her own words (Heritage \& Robinson, 2006).

Although Hoang's two general-inquiry questions both aim to elicit Mi's major concern, it is worth noting that the first one seems more general than the second, as it allows her to voice multiple concerns she may be experiencing. The word khai ('tell') implies that Mi should disclose all the information related to her health issues, regardless of whether they are minor or major, or biomedical or psychological. The second general question (containing the word dau ('trouble')), by contrast, exclusively indexes the symptoms, and invites Mi to identify one specific biomedical ailment.

Hoang's deployment of these two information-seeking inquiries can be interpreted in two ways: either he is chaining two questions in one turn, or his second question is a self-initiated repair within the same turn-constructional unit (Schegloff, Jefferson \& Sacks, 1977). The first interpretation seems implausible, as Hoang rushes through (Schegloff, 1982; symbolised by '=') the first inquiry with a clipped sound at the particle \#đi\#. In so doing, he voices the second question without creating a slot for Mi's response. The absence of this slot violates the rules for turn-taking (Sacks et al., 1974). In addition, both questions have a roughly similar focus on Mi's concern, which suggests that Hoang is trying to paraphrase his previous inquiry in order to be understood more easily. Mi's fully-endorsed lay diagnosis of her ailment (Pomerantz, 2002), suy nhươc ('physically weak'), followed by her mention of her symptom (i.e., pimples), seem more compatible with the second interpretation than the first one. In short, the second question at line 1 is more likely to be a self-initiated repair than part of a question chain.

Though general-inquiry questions encourage the patient to present their health issue in their own terms, some of them also constrain the patient's presentation, as seen in Extract 4. Patient Phong has had her ailment treated before at another health centre, but this is the first time she has come to this hospital (not shown). After the greeting, doctor Quynh commences the information-seeking stage with a general-inquiry question which communicates her lack of prior knowledge of the patient's concern.

Extract 4

\begin{tabular}{|c|c|c|c|}
\hline $\mathrm{D}: \rightarrow \begin{array}{l}d a ́ \\
c a ́ i\end{array}$ & $\begin{array}{l}r \hat{\hat{o}}: i \\
\operatorname{ch} \hat{\hat{o}}+\uparrow m \hat{o}\end{array}$ & $\begin{array}{l}\text { giìt } \\
\text { chị }\end{array}$ & $Đ A U$ \\
\hline $\begin{array}{l}\mathrm{HON} \\
\text { lem }\end{array}$ & $\begin{array}{ll}\text { well } & \text { now } \\
\text { PRT } & \text { where }\end{array}$ & older + sister & \\
\hline
\end{tabular}

$\begin{array}{lllll}2 & \text { di } & k h a ́: m \text { ri } & \text { [chi } & \text { DPho::ng? } \\ \text { go examination } & \text { PRT } & \text { older+sister Phong }\end{array}$ 'Well. What problem has brought you here, Phong?'

3 P: $\quad\left[{ }^{\circ}\right.$ đâ:::y nì:o ] (0.7) this PRT

'This'

4 đây ni::

this PRT

'This' ((the patient points to her arm))

Although ostensibly a general-inquiry question, Quynh's question (lines 1-2) is not general at all, as it elicits a specific piece of information: the location of the pain. With strong emphasis on the word $Đ A U$ ('problem'), Quynh's question embeds a presupposition that Phong has a biomedical rather than a psychological concern. Therefore, in presenting her health condition, she has no option but to point out the physical pain site to Quynh.

Let us examine how Phong does this. In response to Quynh's question, Phong makes an early start in her description (line 3), before the actual completion of Quynh's turn, in order to pinpoint the location of her pain. Although the particle ri (line 2) marks a place of possible syntactic completion (Sacks et al., 1974) and meaning completion, it is produced with level, not rising, intonation. As Vietnamese interrogation is marked by very high rising intonation (Luu, 2010), Quynh's level intonation here signals that her turn will be extended through further additions. However, Phong anticipates that Quynh will complete her meaning soon, and that she should join the talk at an appropriate transition-relevance place (Sacks et al., 1974). Quynh's further talk past the anticipated completion point (i.e., chi Phong, 'Phong') generates a transitional overlap onset of a tag-positioned address term (Jefferson, 1973). But this terminal overlap also runs the risk of impairing Quynh's ability to hear Phong's turn, as evidenced by Quynh's silence of 0.7 seconds, after which Phong has to repeat her response (line 4). Since Quynh's question constrains Phong's answer to the location of the pain, Phong uses the deictic phrase đây nì ('this') to mark this site. Needless to say, this minimal answer does not convey the pain status adequately: Quynh also needs to carry out a physical examination and ask further questions before she can grasp the whole situation.

\section{Same follow-up visits}

In the view of Robinson (2006), the doctor's method of eliciting follow-up concerns aims to (i) expose their own knowledge of a specific concern; (ii) look for an evaluation of, or an update on, a specific concern; and (iii) claim their prior knowledge of the concern in question. For this reason, doctors often ask patients to assess their own health recovery or present any new concerns. However, SFs in the consulting room are somewhat different from those in the ward in terms of the doctor's medical responsibilities. A doctor in the consulting room does not monitor the patient's health progress on a daily basis. Rather, their main duty is to receive all patients as soon as they enter the hospital, perform medical examinations, and then classify them as inpatients, outpatients, and consulting patients so that they can be referred 
to specific units. The doctor may examine the same patient when they come to the hospital for a follow-up; however, other doctors attend the patient during that hospitalisation. Therefore, their knowledge of the patient may not be as great as that of a doctor in the ward.

Extract 5 is an interaction between doctor Nam and patient Huong. Huong has had disc herniation in her spine for a long period.

\section{Extract 5}

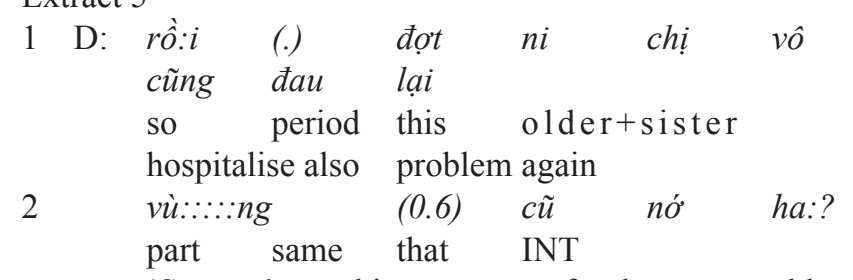

'So, you're seeking treatment for the same problem again?'

$3 \quad(0.5)$

4 P: $d a: \cdots$

yes

'Yes'

$5 \quad(0.2)$

6 D: vùng lung đây Thi:?

part back this PRT

'It's in this part of your back?'

$7 \mathrm{P}$ : \#hắn\# có ĐAU (.) có giảm (0.2) \#nhu rúa\# bác

it PST pain PST better like

that doctor PRT

'The pain's somewhat better, doctor'

$8 \quad(0.2)$

9 D: dạ rồ $:: i$

HON OK

'OK'

The visit opens with Nam's gloss-for-confirmation question (lines 1-2), which makes Huong's response an immediately relevant next action. Nam's question is delivered with a long sound stretch on the word vù::::ng ('part') and a 0.6 -second pause in mid-turn; both of these behaviours presumably express Nam's difficulties in recalling the patient's previous concern. His failure to recall it precisely leads him to adopt a general-but-safe word $c \tilde{u}$ ('same') in initiating the problem presentation. This turns out to be a good solution, as it receives a conforming answer from Huong (line 4). It is not until this point that Nam launches a third-turn repair (Schegloff, 1997) that substitutes the concern's name for the word cũ ('same') through another declarative question (line 6). In response, Huong volunteers a general assessment of her pain (line 7).

In this consultation, Nam's information-seeking acts exhibit his prior knowledge of Huong's recurrent concern. Syntactically, each of his two questions (lines 1-2, 6) is designed in the form of a declarative with a B-event. This strategy favours a 'yes' response (Boyd \& Heritage, 2006), an indicator of a strong epistemic stance. Furthermore, such lexical items as lại ('again'), cũ ('same'), and nó' (demonstrative 'that') indicate that Nam has dealt with this concern before. Hence, we know that this is a SF. Nevertheless, Nam does not elicit Huong's assessment of her recovery - a basic step in a follow-up visit (Cordella, 2004) — to see if the previous treatment method has worked or not. It can be inferred that Nam has neither attended, nor given any treatment to, Huong during her previous hospitalisation. Rather, he only performed a brief examination in her last visit, and then referred Huong to another doctor in the wards.

While Nam's information-seeking approach is quite characteristic of a SF in the consulting room, this is not true of the approach taken in Extract 6, in which Quynh's elicitation is more appropriate for a first visit. Trang is a consulting patient who came to this hospital for treatment of chronic pain six months ago. On that occasion, she bought some traditional medicine to take at home. Now she has come back for a follow-up check to buy more of this type of medication. Extract 6

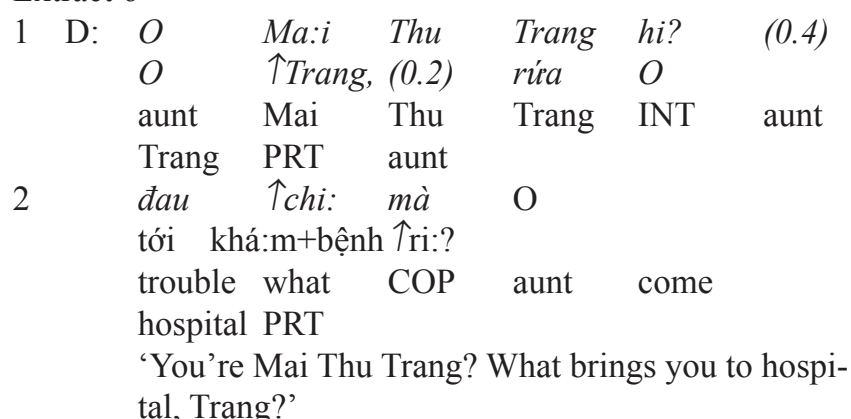

3

(1.4)

4 P: đa:o rúa đa:o tro::.:ng (0.3)

toàn thân luôn (0.4)

pain COP pain inside throughout

body PRT

'I have pain throughout my body'

móng+ta:i móng+chân gì: là-

$\begin{array}{llll}\text { (.) tróc } & h(h) \hat{e} t & (0.6) & \\ \text { fingernail } & \text { toenail all } & \text { COP } \\ \text { come }+ \text { off } & \text { PRT } & & \end{array}$

come+off PRT

'My fingernails and toenails have all come off'

6 >cái khớp \#này\# là coai+nhu

đa:o hết rồi $<$

CLA joint this COP look ache all PERF

'These joints have been aching for ages'

$7 \quad(0.2)$

8 D: $d a::$

$\mathrm{OK}$

'OK'

$((94$ lines deleted $))$

$102 \mathrm{D}:$ dạ:: (0.2) co:n cũng có

điều+tri cho $O$

yes offspring also PST ex

amine for aunt PERF

103 con biết mà,

offspring know PRT

'Yes, I'm with you, as I've examined you before'

As can be seen in lines 1-2, doctor Quynh initiates the problem presentation as if Trang's problem were new, and with no indication that Trang has been treated for this issue previously. The question marker đau chi ('what (trouble)') exposes her minimal knowledge of Trang's concern, and so 
implies that Trang's ensuing information will be new to her. In the same vein, Trang produces a three-part list (Jefferson, 1990) of current concerns (lines 4-6) as if this were her first meeting with Quynh. The pain in her fingernails, toenails, and especially her joints is a long-standing problem, and was probably raised with the doctor during her last visit (as it is chronic). However, Trang's presentation shows no indication that these concerns have been voiced before. The conversation continues with the history-taking and examination of Trang's main concern (i.e., patellofemoral arthritis; not shown). It is not until Quynh admits that she examined Trang for the same concern before (lines 102-103) that the visit type becomes clear.

This section has presented two SFs in the consulting rooms of two different hospitals. The two doctors involved have initiated the problem presentation differently. The first consultation (Extract 5) exhibits the usual pattern found in a same follow-up visit in the consulting room, whereas the second (Extract 6) gives the impression that the visit is new. Let us consider some possible reasons why the doctor initiated the problem presentation in this manner in the latter extract. The doctors in the consulting rooms have to deal with a large number of patients every day, and they examine each patient once only. Outpatients or inpatients will return for follow-up treatment in hospital after a short period, but consulting patients do not follow a specific timeframe: they return anytime they feel it is necessary. For instance, patient Trang in Extract 6 has returned after six months. This long hiatus likely made it difficult for Quynh to recall the patient's previous concern. In addition, Vietnamese patients sometimes neglect to bring their medical record with them when they come for a check-up. This means the doctor has no record to refer to prior to the consultation.

\section{Different follow-up visits}

Although DFs are labelled as 'follow-ups', the patient and the current doctor have not met each other before to deal with the current concern. ${ }^{7}$ In this type of follow-up, the doctor thus has to look at the patient's medical record, so that some doctors communicate with their patients as if this type of follow-up were a first visit.

Extract 7 is an interaction between doctor Nam and patient Tam. This is Tam's third treatment course at this hospital.

\section{Extract 7}

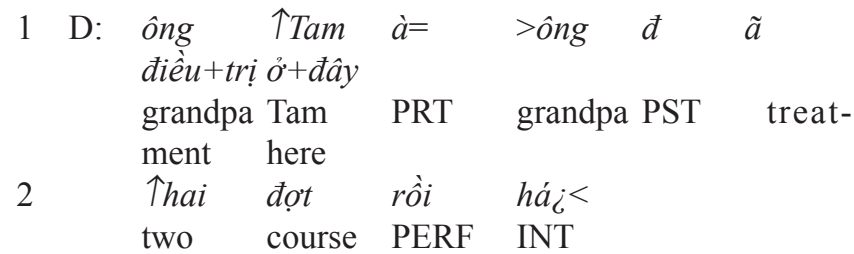

'You've undergone two courses of treatment here before, Tam?'

$\begin{array}{lll}3 & & (0.2) \\ 4 & \text { P: } & \text { da: }: \\ & \text { yes } \\ & \text { 'Yes' }\end{array}$

5 D:

Trước đau chi ông? visit last problem what grandpa

'What was the problem on your last visit?'

$6 \quad(0.2)$

7 P: $d a=$ thoái $+h o ́ a+\uparrow k h o ́ p$

HON osteoarthritis

'Osteoarthritis'

$8 \quad(0.2)$

$9 \mathrm{D}: \quad \grave{a}$ :

oh

'Oh'

10 P: $d a$

yes

'Yes'

$11 \mathrm{D}:$ đơt ni vô lại cũng bị::

(0.4) time this hospitalise again

also suffer

12 >đau [chồ đó luôn $<$ ? ]

problem part that PRT

'You're seeking treatment for the same problem again?'

$13 \mathrm{P}: \quad[(d a ̣)$ hắn hắn hắn ] Tcó

đõ $\quad$ rồi chì $\quad[v o \hat{o}::]$

yes it somewhat better PERF

now hospitalise

'Yes, it's somewhat better, and now-'

$14 \mathrm{D}: \quad[h a ̀: \quad]$

oh

'Oh'

$15 \quad(0.6)$

$16 \mathrm{P}: \quad$ (cho-) >đợt ni mần+răng< (0.3)

for course this how

17 diều+trịcho Tlèng luôn

treatment so+that recover PRT

'I want another course of treatment so that I can recover completely'

18 D: rồi:

$\mathrm{OK}$

'I see'

Judging from his B-event question in lines 1-2, Nam read Tam's medical record before the consultation. First of all, Nam's turn design uses an alternative question with the interrogative particle há (line 2) to express a strong epistemic stance towards the concern in question (Ngo, 1999). In addition, Nam's use of the numerical indicator hai dott ('two courses of treatment'), instead of the one course that would be more usual in a follow-up visit, tells us that he has read the patient's record. Tam's conforming answer treats Nam's prior knowledge as correct (line 4).

Nam proceeds with a non-alternative question at line 5 to elicit Tam's last concern. This question seems to contrast with his previous one (lines 1-2) in terms of its epistemic stance towards Tam's concern. It implies that Nam either did not read the medical record (only reading a slip of paper given to him by the nurse in charge of Tam's record), or is posing an examining question (Athanasiadou, 1991) to test whether Tam can name his ailment. The latter possibility turns out to be wrong, based on Nam's uptake (line 9) of Tam's answer (line 7). The stretched à:-preface (line 9) 
here indicates that Tam's information is new to him. Overall, this question design also demonstrates that Nam did not examine Tam on his last two visits, which in turn makes this a DF.

In response to Tam's presentation (line 7), Nam begins to elicit the current concern (lines 11-12). He launches his elicitation with a 0.4 -second pause in the middle, then rushes through (symbolised by ' $><$ ') to indicate the continuity of talk. His declarative question in lines 11-12 is institutionally appropriate for follow-up visits, given that follow-ups monitor the previous concern for the sake of managing the treatment on an ongoing basis (Cordella, 2004). Tam responds with the aligned answer 'yes'. This is followed by an expansion which gives a general rationale for his current hospitalisation (lines 13, 16-17).

\section{Ward}

As mentioned in Section 1, after their meeting in the consulting room is over, an inpatient or outpatient is transferred directly to the ward, where other doctors examine them again and monitor their problem for a period of three weeks. Each patient receives attention from a doctor, a nurse, and a hospital orderly during their hospitalisation, but the doctor is held fully accountable for the patient's recovery.

\section{First visits}

Extract 8 illustrates doctor Si's elicitation in a first visit with patient Trinh in the ward. Si uses a history-taking question (Heritage \& Robinson, 2006) to open the business of the visit. Extract 8

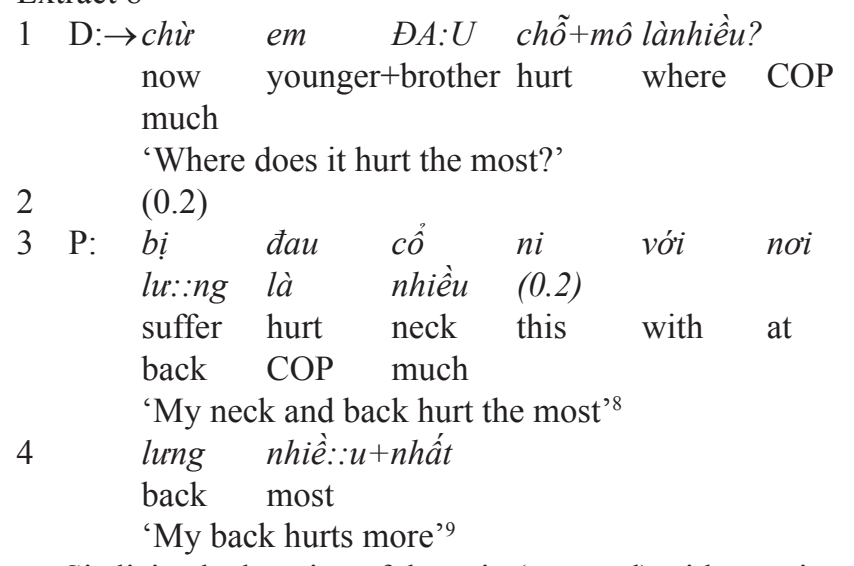

Si elicits the location of the pain (arrowed) with an orientation to a concrete, current symptom (Robinson \& Heritage, 2005). As patient Trinh's concern has already been documented by another doctor before this visit, Si has presumably retrieved it from his medical record. Accordingly, Si's question is launched with a strong epistemic stance. He uses the word $Đ A: U$ ('hurt'), which expresses certainty that Trinh is suffering from physical pain. The word nhiều ('much' in the gloss, but 'most' in the translation) denotes that Trinh has pain in at least two parts of his body, one of which is more painful than the other(s). In referring to two body parts (i.e., the neck and the back), Trinh confirms Si's presupposition as valid and correct. Although the question at line 1 communicates the fact that $\mathrm{Si}$ has some pre-existing knowledge of Trinh's concern, it invites him to describe the pain de novo, thus positioning $\mathrm{Si}$ as a relatively unknown recipient (Heritage \& Robinson, 2006)

As Trinh has been referred by another health professional, Si's question is formulated more like a history-taking question than a problem-presentation one. He already has some details of Trinh's major concern from the referral letter, which establishes mutual understanding of the patient and achieves alignment not only between the patient and the attending doctor, but also between these two participants and the referring doctor (White, 2011). He now only wishes to establish the location of the most painful area. However, even though Si already has the necessary information about Trinh's health, and even though Trinh knows that $\mathrm{Si}$ already has this information, Si projects his question like a problem-presentation question (rather than a history-taking question), plus Trinh responds as if it were a problem-presentation question (rather than a history-taking question). Si thus designs his question as if he were dealing with a follow-up concern rather than a new one, as this approach reveals his foreknowledge of Trinh's health problem.

In another interaction with patient Nhu in Extract 9, Si again frames a history-taking question to initiate the problem presentation. However, this question has a narrower scope than the one in Extract 8.

Extract 9

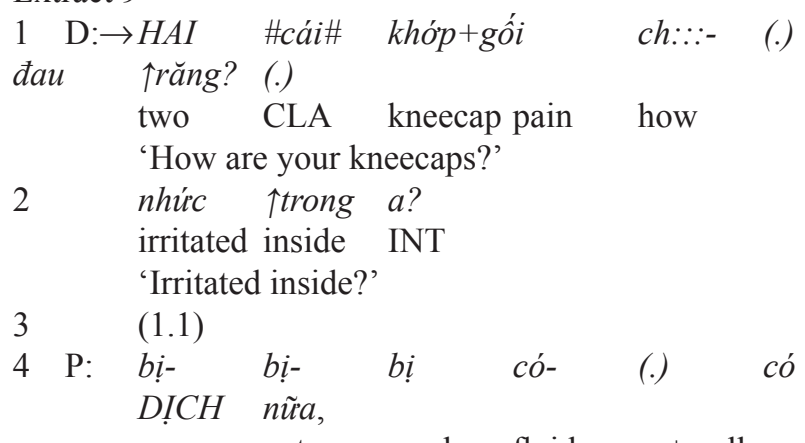 $5 \quad(0.3)$
6 D: $\grave{a}:$ :
oh
'Oh'
7 P: <em coai noi cái phi:m với cá $>$ $>$ PRT CLA x-ray with CLA 8 siêu+âma tề ultrasound PRT PRT
'Please ${ }^{10}$ have a look at the X-ray and the ultra- sound result'
9 D: ${ }^{\circ}$ rồi ${ }^{\circ}$
$\mathrm{OK}$
'OK' 'And they've been producing fluid as well'

Si projects a single turn consisting of two turn-construction units (TCUs) to elicit the main concern: the first TCU is a general-inquiry elicitor and the second is a symptom-for-confirmation elicitor (Heritage \& Robinson, 2006). The first one (line 1) is projected with a deletion (ch::-), 
which was likely intended to be chù ('now'), followed by a micro pause, and then with further talk to complete the turn. The second TCU (line 2) has stress on nhúc ("irritated', symbolised by underlining). This turn is syntactically a declarative, but produced with an upward-intoned ending (Luu, 2010), an indicator of Vietnamese interrogation. The declarative component formulates a 'B-event' (i.e., information known to B (the addressee), but not to A (the addressor); Labov \& Fanshel, 1977).

Let us consider Si's two-TCU turn at lines 1-2. At first glance, it seems that $\mathrm{Si}$ is chaining two questions in one turn here; in fact, he is doing a self-initiated repair in order to fine-tune his turn. This involves aborting the previous question and producing a new one, on the basis that the first question is more general and may fail to elicit accurate information. The presence of this repair is evidenced by a very short pause between the two questions with no slot available for Nhu's response, and the absence of a response to the first question from Nhu. Additionally, both questions address the same issue (i.e., Nhu's kneecaps). Declarative questions are strongly polarised in both positive and negative directions; thus, the second question, which contains the leading word nhúc ('irritated') is polarised in the positive direction in order to invite a preferred next action (Pomerantz, 1984).

Nhu's response demonstrates that she is addressing the second question. Though her stuttered answer (line 4) is a nonconforming response (Raymond, 2003) to the second question, which contains neither a 'yes' nor a 'no', it appends another piece of problem-indicative information (Nishizaka, 2011) to the second rather than the first question. The word nũa ('as well') means that something has been added to the previous opinion (i.e, Si's word nhúc ('irritated')). Si receipts Nhu's presentation with a marked confirmation $\grave{a}$-preface (line 6) in order to flag a change in his locally current state of information (Heritage, 1984). As it is produced in a stretched-out fashion, $\grave{a}$ indicates that $\mathrm{Si}$ has just received Nhu's information, and thus registers that her concern is new. His change-of-state token then invites Nhu to expand her talk (lines 7-8) in order to justify her folk diagnosis, có dịch ('They've been producing fluid') at line 4 .

Si's question (lines 1-2) is shaped by a preceding interaction (Heritage \& Robinson, 2006), which, in this case, is the patient's consultation with another doctor in the consulting room. It embodies Si's claim to some prior knowledge of Nhu's concern (i.e., pain in the kneecaps) before the consultation. This question design conforms to the conversation norm of "not to tell things already known" (Terasaki, 2004, p. 178). However, Si seems unsure of the severity of the pain, and thus seeks confirmation of the symptom (in the second TCU; line 2). Through this question, Si also obtains further details (i.e., there is fluid on Nhu's kneecaps) from the information she proffers. Overall, Si's questions bypass the problem presentation, and set up an agenda for Nhu's response which revolves exclusively around the problem with her kneecaps. These questions thus sharply constrain her answers. In short, Si frames the questions as if he had seen Nhu before, and as if this were a follow-up visit.

\section{Same follow-up visits}

As the doctors in the wards monitored the patient's health status on a daily basis during their previous hospitalisation, the key information they need to elicit in the present visit is related to assessing the patient's recovery since they left the hospital. This is exemplified in Extract 10. Patient Tu has undergone a three-week course of treatment before for the same concern (i.e., back and leg pain).

\section{Extract 10}

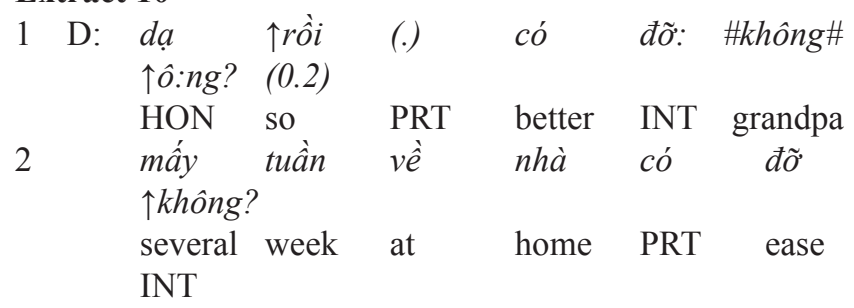

'So, has it got better? Has it got better during the several weeks you've been at home?'
3 P: đõ: (.) đươ:c (0.2) có::>sá:
$u+$ muooi phần + trăm<
better get about sixty percent
'Yes, it has. I'm back to about sixty percent of nor- mal'

Yen starts the consultation with an appositional beginning, da rồi ('so'). This is followed by an alternative question (line 1) that seeks a minimal answer concerning Tu's evaluation of his previous problem. However, after only 0.2 seconds, Yen quickly makes a self-initiated repair by inserting a relative temporal specification, mấy tuần ('several weeks'), and a location, về nhà ('at home'), into the unit of talk (line 2). The repaired question, which specifies the duration and location of the recovery period, encourages a much clearer and more detailed response from Tu. In doing this, Yen is adhering to the principle of recipient design ${ }^{11}$ (Sacks et al., 1974). Moreover, the use of an alternative question with the pair of words có ... không sets a restricted action agenda requiring a response of either 'yes' or 'no'.

There is evidence that Extract 10 is a SF. Firstly, even though Yen curtails the subject of her question, Tu can understand what she is referring to (through his answer at line 3 ). Notice the ellipsis of the subject of đơ ('better') in lines 1-2. ${ }^{12}$ Ellipsis is commonly used to connect the current turn of talk with its prior turn (Drew, 2013), yet there is no turn preceding Yen's question. Rather, this subject ellipsis implies an assumption that both interlocutors are talking about Tu's pain, and that Yen's knowledge of this concern is shared by Tu. Secondly, the word đõ ('better'; lines 1-2) presupposes that $\mathrm{Tu}$ has not only had something wrong with his health, but also received some type of treatment during his previous visit. Thirdly, Yen understands that Tu had not fully recovered when he was discharged from the hospital last time. Lastly, Yen's phrase mấy tuần về nhà ('the several weeks you've been at home') reveals that she has kept an exact record of Tu's leaving date, which is officially issued in writing by the attending doctor. In brief, Yen's verbal resources thus demonstrate that she took care of Tu during his last hospitalisation.

In line with Yen's questioning, Tu also strategically for- 
mulates his turn (line 3) to present himself as a follow-up patient. The first piece of evidence is that, despite the use of subject ellipsis in both turns, Yen and Tu can implicitly understand what they are talking about (i.e., Tu's pain). Another piece of evidence is his adoption of the word $d \tilde{o}$ ('back'), which shares the same interactional action as in Yen's discourse. The word $₫ \tilde{o}$, followed by a micro pause, can be metaphorically interpreted as vâng, đõ ('Yes, it's back'), a so-called marked confirmation (Stivers, 2011). However, Tu does not complete his turn at đõ, but rushes through to extend it to đurợc có sáu muooi phần trăm ('back to about sixty percent of normal') after a possibly complete TCU has been generated. This expansion gives the incorrect impression that đõ ('back') is part of the whole turn đơ được có sáu murơi phần trăm ('I'm back to about sixty percent of normal'), and that Tu's TCU is a nonconforming response to Yen's alternative question (which seeks only a 'yes' or 'no' answer). Tu's additional unit of talk, which makes an approximate numerical assessment of the pain, is another plausible explanation for his follow-up concern.

While doctor Yen in Extract 10 elicits a recovery assessment, doctor Lam in Extract 11 summarises the patient's concerns from his last visit.

Extract 11

$$
1 \text { D: } \begin{aligned}
& \text { Tô.:.nng } \\
& \text { grandpa } \\
& \text { 'You' }
\end{aligned}
$$

2 P: $d a: \cdots$

yes

'Yes'

$3 \quad(0.2)$

4 D: vờ:.:- (0.2) trước vô này- (0.7)

$\begin{array}{lllll} & \text { uh } & \text { previous } & \text { hospitalise } & \text { PRT } \\ 5 & \grave{a}: \cdots & \text { (.) }>\text { c) } & \text { cái lung } & \text { nà:y, }<\end{array}$ uh ache CLA back PRT 'Your previous concern was backache'

$6 \quad(0.3)$

7 P: vâ::ng yes

'Yes'

$8 \quad(1.1)$

9 D: rồ:i $\uparrow$ chi nũa ông hè::? and what else grandpa PRT

'And what else?'

$10 \quad[>$ dau $\quad k i \quad$ lung $<$ ] ache CLA back

'Backache'

11 P: [truóo::c là ] vô: (.) đau ki lu:ng previous COP hospitalise ache CLA back

'I had a backache during my previous hospitalisation'

12

$13-(0.3)$

$\left.\begin{array}{llll}\mathrm{D}: & \uparrow \grave{u}: \ldots \quad(0.2) & {[v i} & \text { à }:-\end{array}\right]$

14 P: [\#mà\# chì] $]$ \#hắn\# Th:

$\begin{array}{llll} & \text { but now } & \text { it } & \text { numb } \\ \text { 'But it's numb now' } & & \\ {[k i \quad c h u n \quad \text { tê: }} & ] \\ \text { CLA leg } \quad \text { numb } & & \end{array}$

CLA leg numb

'My leg's numb'

16 D: [\#mà\# chì̀:: là \#hắn\# ] tê: but now COP it numb

'But it's numb now'

$17 \quad(0.8)$

18 P: chì \#hắn\# qua- qua- (0.3) qua

$T \hat{E}$ :

now it become numb

'Now it's become numb'

$19 \quad(0.3)$

20 D: $d a: \cdots$

$\mathrm{OK}$

'I see'

$21 \quad(0.7)$

22 P: mà giù:: cái lư:ng ĐÕ:::

but now CLA back better

'But my back's better now'

$(0.4)$

24 D: à:.: (.) cái lung đõ: ¿i

oh CLA back better

$25 \mathrm{P}:{ }^{\circ} d a:^{\circ}$

'Oh, your back's better'

yes

'Yes'

((40 lines deleted - the patient takes the medication and the doctor assesses the previous concern))

66 D: rúa chù: $\grave{a}-\quad$ (.) dọt $n i$

ông vô ông

so today uh period $t h$ i $s$

grandpa hospitalise grandpa

67 m- mong+muốn điều+trị cái+个chi:?

wish treatment what

'So what's your main concern today?'

$68 \quad(0.3)$

69 P: mong+muốn à: (.) cái chun

want uh CLA leg

'I want some treatment for my leg'

((8 lines deleted - they talk about Sinh's leg, which is not the focus of discussion in this extract))

77 P: lưng cũng châm bổ+túc \#nũ:a\#

back also acupuncture extra PRT

'My back also needs extra acupuncture'

Lam starts the consultation abruptly, without any greeting or seeking of personal details. He neither elicits Sinh's assessment of his health nor establishes the reason for his return. Rather, he reviews Sinh's previous concern (i.e., backache) in the form of a declarative (lines 4-5) and, after a 1.1-second silence, asks about other previous concerns that he cannot remember (line 9). The declarative turn (lines 4-5) expresses a very strong epistemic stance toward Sinh's problem. It supports the claim that Lam has monitored Sinh's health quite well, and so this is a SF. Lam's questioning turn (line 9) presupposes that Sinh had at least two concerns on his last visit, and that Lam is trying to identify the remaining 
one. However, Sinh's response (line 11), delivered in a delayed manner after 0.6 seconds, foreshadows a non-aligned stance against the action pursued by Lam's question. This non-answer response resists the question by challenging its assumption and relevance (Lindström, 2009). In fact, Sinh does not provide the information sought by the question, but produces a full repeat to confirm the propositional content of Lam's description at lines 4-5 (Schegloff, 1997), as well as insist on his epistemic primacy prior to volunteering the new concern (lines 14-15).

Exploiting Lam's reviewing question, Sinh then introduces his new concern (i.e., numbness in his leg) without Lam needing to elicit it. This concern is mentioned three times consecutively (lines 14-15, 18). The first one (line 14) serves as an announcement to provide good grounds for his follow-up visit. However, it fails to obtain any feedback from Lam after a lengthy silence of 2 seconds (line 14). This lack of feedback can be interpreted in two ways. First, as this turn is produced in terminally overlapping talk (Jefferson, 1984) with Lam's previous one, this overlap might be impairing Lam's ability to hear the beginning of Sinh's turn, even though only the appositional beginning mà chù ('but ... now') is overlapped. Alternatively, hắn ('it') might be referring anaphorically to lung ('back'), not cataphorically to chun ('leg'). Therefore, Sinh partially repeats his prior turn with an emphasis on chun tê ('My leg's numb') to specify which part of his body is numb (line 15). Lam acknowledges this by supplying another repetition (line 16) in the form of a declarative question. In response, Sinh makes a full repeat for the third time (line 18) as a means of asserting agency or authority over the proposition (Stivers \& Hayashi, 2010).

In lines 26 to 65 (not shown), the conversation veers back to Sinh's previous concern (i.e., backache) without touching upon the numbness in his leg. Realising that Sinh's backache has subsided, Lam begins to elicit his main concern (lines 66-67). On the face of it, this information-seeking act indicates that this is not a follow-up visit, as Sinh's current problem (i.e., the numbness in his leg) differs from the previous one (i.e., backache). Nevertheless, as the consultation develops, Sinh reveals that his back needs extra acupuncture (line 77).

In short, in SFs in the ward, the doctors tend to establish themselves as an insider towards the patient's health concern. This is indicated by the fact that their discourse largely focuses on the patient's assessment of their health after a specific point in time, and on the task of eliciting new concerns.

\section{Different follow-up visits}

Extract 12 is an encounter between doctor Chu and patient Sang in the ward. Sang has just finished one course of treatment and has now returned for a follow-up.

Extract 12

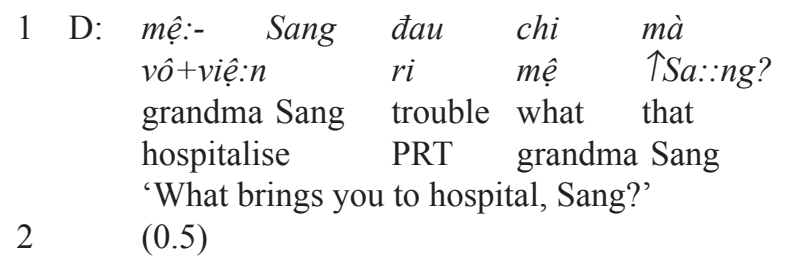

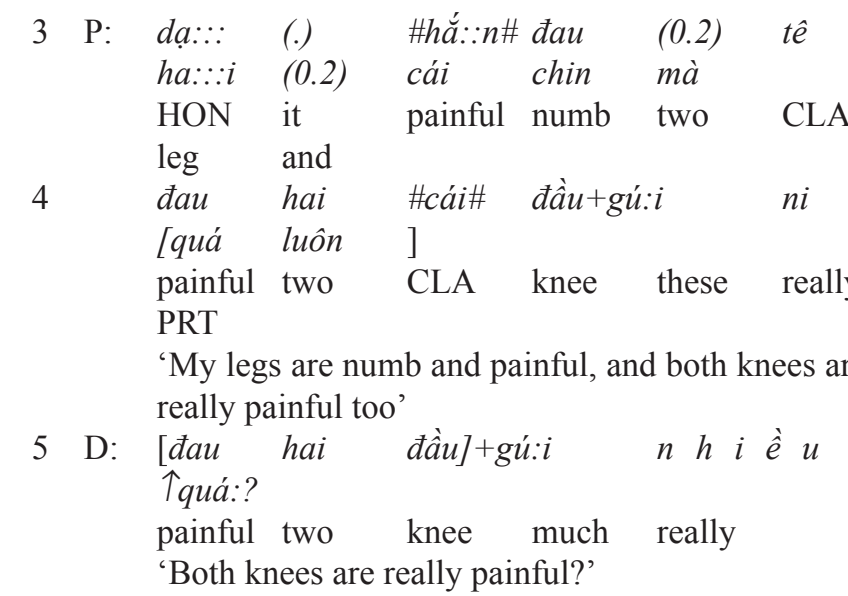

Right at the outset of the consultation, Chu displays his lack of knowledge of Sang's medical history with a general-inquiry question (line 1). The question marker đau chi ('what (trouble)') encourages Sang to present something new to Chu. By the same token, Sang's two concerns related to her legs and knees (lines 3-4) are disclosed as if they were unknown to Chu. Hence, this exchange gives the impression that it is a first visit.

\section{DISCUSSION}

According to Robinson (2006), the question format that the doctor uses to solicit the patient's presenting health problem conveys the doctor's understanding of the patient's reasons for seeking medical treatment. This understanding is expressed, at least in part, in terms of the epistemic stance that the doctor assumes vis-à-vis the patient's problem. As shown in Section 4, this stance varies with the clinical setting-at least, for first visits and SFs. In the consulting room, some doctors display a lack of familiarity with the patient's concern in first visits (Extracts 3,4), while, in SFs, they might not indicate that they have monitored the patient's health in their previous hospitalisation (Extracts 5, 6). Indeed, some doctors even show a complete absence of knowledge of the patient's concern (Extract 6). This contrasts with the situation in the ward. In first visits, the doctors in this setting might express pre-existing knowledge of this issue (Extracts $8,9)$. In SFs, the doctor may communicate a proper understanding of the patient's situation by eliciting a recovery assessment (e.g., Extract 10), or by summarising the problem from the previous consultation (e.g., Extract 11). As far as first visits and SFs are concerned, then, the essential difference between the elicitation strategies used in the consulting room and the ward is that, respectively, the doctor expresses a weak and strong epistemic stance towards the patient's problem.

However, in DFs, the difference between these two clinical settings is not as clear, as the approach to problem elicitation employed in this type of visit depends on how much the doctor knows about the patient's medical history (if anything at all). Thus, the doctor in Extract 7 understands that the patient is in hospital for a follow-up visit, but he does not seem to know about the patient's previous health concern, while it is likely that the doctor in Extract 12 has not read the patient's medical record before the consultation. 
An additional finding is that the clinical setting has some bearing on the use of inappropriate elicitation formats in our data. In the consulting room, the doctor may open a follow-up visit using a question designed for eliciting a new concern instead (Extract 6). Notably, this particular case occurs in a SF, in which the doctor tends not to monitor the patient's progress on a regular basis. It sometimes happens that a new-concern design is used in a follow-up in the ward as well (Extract 12). This mostly occurs in DFs, and is again plausibly attributable to the fact that the patient's recovery is not monitored regularly in this type of consultation. The opposite situation can also arise in this clinical setting: some questions in first visits in the ward are launched in a manner more appropriate for a follow-up (Extracts 8, 9). This is explicable when we consider that patients in this setting have been referred by a doctor in the consulting room (see Section 1), and that the attending doctor is therefore likely to have gleaned some knowledge of the patient's health status from their medical record.

\section{CONCLUSION}

This study has highlighted differences between the elicitors utilised by doctors in the consulting room and the ward in the Vietnamese context. Specifically, doctors in the consulting room often use elicitors that convey a weak epistemic stance vis-à-vis the patient's presenting concern, while those in the ward tend to use elicitors that express a strong epistemic stance. In addition, this contrast is present in our data regardless of whether the consultation is a first visit or a same follow-up, though it is less clear for different follow-ups. In addition, we have shown that the clinical setting plays a role in determining the incidence of inappropriate elicitation formats in medical consultations. The precise manner in which each of the consulting room and the ward operates is, of course, a feature of the Vietnamese public hospital system itself. Hence, the overall contrast between the elicitors and elicitation formats employed in these two settings illustrates how, on a more general level, the institutional context can have an effect on doctor-patient communication.

Our findings also have implications for the provision of medical care in this system in the ward setting especially. Given that the doctor's initiation of the problem presentation shapes the patient's disclosure of their main concerns, which in turn influences the trajectory of the consultation thereafter, it is crucial that the doctor acquire a thorough understanding of the patient's health concern from multiple sources (e.g. the patient's medical record, or information from nurses) before they attempt to elicit the patient's health issue. Equipped with sufficient knowledge of this issue, the doctor will then be more likely to employ an appropriate elicitor, and this may save them time and energy. The use of an appropriate elicitor might also be expected to trigger the patient's disclosure of the exact information that the doctor requires.

\section{ENDNOTES}

1 Throughout this paper, we use the gender-neutral pronoun 'they/their etc..'
2 The doctors in the overseas studies were English speakers, not Vietnamese ones, so the consultations were in English.

3 We use the following abbreviations in the interlinear glosses: CLA - classifier; COP - copula; HON - honorific; INT - interrogative; PERF - perfect aspect; PRT - particle; PST - past tense.

4 The hierarchical structure of Vietnamese society is evident in a wide range of kinship terms used for addressing and referring to others. In employing these terms, the speaker counts the addressee as a relative or family member (Tran, 2006), regardless of whether they are related or not (Ho, 1997). The selection of kinship term in a given set of circumstances is conditioned by the age, marital status, social class, degree of intimacy, and gender of each interlocutor, and also by local customs (Huynh, 1989). Needless to say, these general observations apply more specifically to medical consultations too. In this type of communication, kinship terms are utilised by interlocutors to show respect towards each other and maintain positive face (Tran, 2013).

5 In morphosyntactic terms, there are significant divergences between Vietnamese and English (Nguyen, 2009). Our main consideration in the translations is to strike a compromise between the naturalness of the English on one hand and faithfulness to the original on the other. For the sake of clarity, we also occasionally include some information that is left implicit in the original.

6 We use a plus (+) sign to join together two words in the Vietnamese transcription or the interlinear morpheme gloss.

7 In other words, the patient was examined by a different doctor on their previous visit.

8 The patients in our corpus often repeat the content of the doctor's question in full as a token of respect.

9 The patient probably meant to say nhiều ho'n ('more') instead of nhiều nhất ('most') in comparing the two body parts. For the sake of clarity, the free translation reflects the (likely) intended rather than actual meaning.

10 To express politeness in imperatives, instead of using xin vui lòng ('please'), Vietnamese speakers may preface their utterance with an address term. Our inclusion of 'please' in the free translation reflects the use of the address term em ('younger brother') with this force.

11 The principle of recipient design refers to the "multitude of respects in which the talk by a party in a conversation is constructed or designed in ways which display an orientation and sensitivity to the particular other(s) who are the co-participants" (Sacks et al., 1974, p. 727).

12 As subject ellipsis is not natural in this case in English, we have rendered the ellipsed subject using the referential pronoun "it".

\section{REFERENCES}

Athanasiadou, A. (1991). The discourse functions of questions. Pragmatics: Quarterly Publication of the International Pragmatics Association, 1(1), 107-122. doi: 10.1075/prag.1.1.02ath 
Boyd, E., \& Heritage, J. (2006). Taking the history: Questioning during comprehensive history-taking. In J. Heritage \& D. Maynard (Eds.), Communication in medical care: Interaction between primary care physicians and patients (pp. 151-184). Cambridge, England: Cambridge University Press.

Byrne, P. S., \& Long, B. E. L. (1976). Doctors talking to patients: A study of the verbal behaviour of general practitioners consulting in their surgeries. London, England: Her Majesty's Stationery Office.

Cordella, M. (2004). The dynamic consultation: A discourse analytical study of doctor-patient communication (Vol. 128.). Amsterdam, The Netherlands: John Benjamins.

Coupland, J., Robinson, J. D., \& Coupland, N. (1994). Frame negotiation in doctor-elderly patient consultations. Discourse \& Society, 5(1), 89-124. doi: 10.1177/0957926594005001005.

Drew, P. (2013). Turn design. In J. Sidnell \& T. Stivers (Eds.), The handbook of conversation analysis (pp. 131149). Malden, MA: Wiley-Blackwell.

Dyche, L., \& Swiderski, D. (2005). The effect of physician elicitation approaches on ability to identify patient concerns. Journal of General Internal Medicine, 20(3), 267-270. doi: 10.1111/j.1525-1497.2005.40266.x

Edwards, V., \& Phan, A. (2013). Managers and management in Vietnam: 25 years of economic renovation (Doi moi). New York, NY: Routledge.

Fancher, T. L., Ton, H., Le Meyer, O., Ho, T., \& Paterniti, D. A. (2010). Discussing depression with Vietnamese American patients. Journal of Immigrant and Minority Health, 12(2), 263-266. doi: 10.1007/s10903-009-9234-y

Gill, V. T., \& Roberts, F. (2013). Conversation analysis in medicine. In J. Sidnell \& T. Stivers (Eds.), The handbook of conversation analysis (pp. 575-592). Chichester, England: Wiley-Blackwell.

Heritage, J. (1984). A change-of-state token and aspects of its sequential placement. In J. M. Atkinson \& J. Heritage (Eds.), Structures of social action: Studies in conversation analysis (pp. 299-345). Cambridge, England: Cambridge University Press.

Heritage, J., \& Robinson, J. D. (2006). The structure of patients' presenting concerns: Physicians' opening questions. Health Communication, 19(2), 89-102. doi: 10.1207/s15327027hc1902_1

Ho, D. T. (1997). Vietnamese-English bilinguals in Melbourne: Social relationships in code-switching of personal pronouns. Monash University Linguistics Papers, 1(1), 41-51. Retrieved from http://search.informit.com. au/documentSummary;dn=322250958933600;res=IELHSS

Huynh, D. T. (1989). Introduction to Vietnamese culture. San Diego, CA: San Diego State University.

Jefferson, G. (1973). A case of precision timing in ordinary conversation: Overlapped tag-positioned address terms in closing sequences. Semiotica: Journal of the International Association for Semiotic Studies/Revue de l'Association Internationale, 9(1), 47-96. doi: 10.1515/ semi.1973.9.1.47
Jefferson, G. (1984). Notes on some orderlinesses of overlap onset. In V. D’Urso \& P. Leonardi (Eds.), Discourse analysis and natural rhetoric (pp. 11-38). Padua, Italy: Cleup Editore.

Jefferson, G. (1990). List construction as a task and resource. In G. Psathas (Ed.), Interaction competence (pp. 63-92). Washington, D.C.: University Press of America.

Jefferson, G. (2004). Glossary of transcript symbols with an introduction. In G. Lerner (Ed.), Conversation Analysis: Studies from the first generation (pp. 13-31). Philadelphia, PA: John Benjamins.

Labov, W., \& Fanshel, D. (1977). Therapeutic discourse: Psychotherapy as conversation. New York, NY: Academic Press.

Lindström, A. (2009). Projecting nonalignment in conversation. In J. Sidnell (Ed.), Conversation analysis: Comparative perspectives (pp. 135-158). New York, NY: Cambridge University Press.

Luong, N. H., \& Le, V. D. (2008). Nghiên cứu lòi chào của nguời Việt và so sánh với lời chào của ngườ Pháp [A study on Vietnamese greetings and a comparison with French]. Paper presented at Hội nghị sinh viên nghiên cứu khoa học, Da Nang University, Vietnam.

Luu, T. K. N. (2010). A brief comparison of Vietnamese intonation and English intonation and its implications for teaching English intonation to Vietnamese EFL learners. VNU Journal of Science, Foreign Languages, 26, 171180. Retrieved from https://js.vnu.edu.vn/FS/article/ view/2554

Ngo, N. B. (1999). Elementary Vietnamese. Boston, MA: Tuttle Publishing.

Nguyen, D. H. (2009). Vietnamese. In Comrie, B. (Ed). The world's major languages (2 ${ }^{\text {nd }}$ ed.; pp. 677-692). London, England: Routledge.

Nguyen, D. T. (2012). Một số đặc điểm giao tiếp giũa bác sĩ và bệnh nhân trong quá trình khám và điều trị bệnh tại Trung tâm Y học hạt nhân và Ung buớu và các khoa lâm sàng tại Bệnh viện Bạch Mai [Some characteristics of communication between doctors and patients during consultations and treatment at $\mathrm{The} \mathrm{Nu}$ clear Medicine and Oncology Centre and Clinic wards in Bach Mai hospital] (Unpublished master's thesis). University of Social Sciences and Humanities, Hanoi, Vietnam.

Nguyen, G. T., Barg, F. K., Armstrong, K., Holmes, J. H., \& Hornik, R. C. (2007). Cancer and communication in the health care setting: Experiences of older Vietnamese immigrants, a qualitative study. Journal of General Internal Medicine, 23(1), 45-50. doi: 10.1007/s11606007-0455-2

Nishizaka, A. (2011). Response expansion as a practice for raising a concern during regular prenatal checkups. Communication \& Medicine, 8(3), 247-259. doi: 10.1558/cam.v8i3.247

Park, Y. (2009). Analyzing medical discourse: The organization of doctor-patient interaction in Korean primary care settings (Unpublished doctoral dissertation). University of California, Los Angeles, USA. 
Pham, T. H. N. (2014). Linguistic and cultural constraints in Vietnamese general practitioners' act of initiating clinical information-seeking process in first encounters with outpatients. Theory and Practice in Language Studies, 4(6), 1125-1131. Retrieved from http://www.academypublication.com/issues/past/tpls/ vol04/06/04.pdf

Pomerantz, A. (1984). Agreeing and disagreeing with assessments: Some features of preferred/dispreferred turn shaped. In J. M. Atkinson \& J. Heritage (Eds.), Structures of social action: Studies in conversation analysis (pp. 57-101). Cambridge, England: Cambridge University Press.

Pomerantz, A. (2002). How patients handle lay diagnoses during medical consultations. Paper presented at the Tenth Annual Symposium about Language and Society Texas Linguistic Forum, Austin, TX.

Raymond, G. (2003). Grammar and social organization: Yes/no interrogatives and the structure of responding. American Sociological Review, 68(6), 939-967. doi: $10.2307 / 1519752$

Robinson, J. D. (2006). Soliciting patients' presenting concerns. In J. Heritage \& D. W. Maynard (Eds.), Cотmunication in medical care: Interaction between primary care physicians and patients (Vol. 20., pp. 22-47). Cambridge, England: Cambridge University Press.

Robinson, J. D., \& Heritage, J. (2005). The structure of patients' presenting concerns: The completion relevance of current symptoms. Social Science \& Medicine, 61(2), 481-493. doi: 10.1016/j.socscimed.2004.12.004

Sacks, H., Schegloff, E. A., \& Jefferson, G. (1974). A simplest systematics for the organization of turn-taking for conversation. Language, 50(4), 696-735. doi: 10.17323/1728-192X-2015-1-142-202.

Schegloff, E. A. (1982). Discourse as an interactional achievement: Some uses of 'uh-huh' and other things that come between sentences. In D. Tannen (Ed.), Analyzing discourse: Text and talk (pp. 71-93). Washington, D.C.: Georgetown University Press.

Schegloff, E. A. (1997). Practices and actions: Boundary cases of other-initiated repair. Discourse Processes, 23(3), 499-545. doi:10.1080/01638539709545001

Schegloff, E. A., Jefferson, G., \& Sacks, H. (1977). The preference for self-correction in the organization of repair in conversation. Language, 53(2), 361-382. doi: 10.1353/ lan.1977.0041

Silverman, J., Kurtz, S. M., \& Draper, J. (2013). Skills for communicating with patients. London, England: Radcliffe.

Stivers, T. (2011). Morality and question design: 'Of course' as contesting a presupposition of ask ability. In T. Stivers, L. Mondada, \& J. Steensig (Eds.), The morality of knowledge in conversation (pp. 82-106). Cambridge, England: Cambridge University Press.

Stivers, T., \& Hayashi, M. (2010). Transformative answers: One way to resist a question's constraints. Language in Society, 39(1), 1-25. doi: 10.1017/S0047404509990637

Terasaki, A. K. (2004). Pre-announcement sequences in conversation. In G. Lerner (Ed.), Conversation analysis: Studies from the first generation (pp. 171-223). Amsterdam, The Netherlands: John Benjamins.

Tran, K. (2009). Examining conversational constraints in Vietnamese patient-doctor communication: A case study. Xulanexus: Xavier University of Louisiana's Undergraduate Research Journal, 6(1), 3-20. Retrieved from http://xulanexus.xula.edu/textpattern/index. php?s=file_download\&id $=20$

Tran, N. T. (2006). Tìm về bản sắc văn hóa Việt Nam [Tracing Vietnamese cultural identity] (5th ed.). Hochiminh, Vietnam: Nhà Xuất Bản Tổng hợp thành phố Hồ Chí Minh.

Tran, Q. N. T. (2013). Refusal face-work strategies in intercultural communication: Refusals reported by Vietnamese speakers of EFL in intercultural workplaces (Unpublished doctoral dissertation). University of Queensland, Brisbane, Australia.

White, S. J. (2011). A structural analysis of surgeon-patient consultations in clinic settings in New Zealand (Unpublished doctoral dissertation). University of Otago, Wellington, New Zealand. 